\title{
BMJ Open Cohort profile: maternal lifestyle and diet in relation to pregnancy, postpartum and infant health outcomes in Vietnam: A multicentre prospective cohort study
}

Cong Luat Nguyen, ${ }^{1}$ Phung Thi Hoang Nguyen, ${ }^{2}$ Tan Khac Chu, ${ }^{3}$ Anh Vo Van Ha, ${ }^{4}$ Ngoc Minh Pham, ${ }^{5}$ Dat Van Duong, ${ }^{6}$ Dung Van Do, ${ }^{2}$ Hong Kim Tang, ${ }^{4}$ Colin W Binns, ${ }^{7}$ Andy $\mathrm{H} \mathrm{Lee}^{7}$

To cite: Nguyen $\mathrm{CL}$, Nguyen PTH, Chu TK, et al. Cohort profile: maternal lifestyle and diet in relation to pregnancy, postpartum and infant health outcomes in Vietnam: A multicentre prospective cohort study. BMJ Open 2017;7:e016794. doi:10.1136/ bmjopen-2017-016794

- Prepublication history for this paper is available online. To view these files please visit the journal online (http://dx.doi. org/10.1136/bmjopen-2017016794).

Received 13 March 2017 Revised 10 June 2017 Accepted 26 July 2017

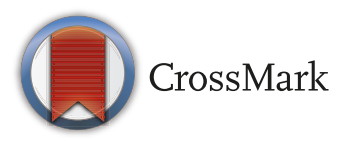

For numbered affiliations see end of article.

Correspondence to

Cong Luat Nguyen;

congluat@gmail.com

\section{ABSTRACT}

Purpose To determine modifiable maternal risk factors for adverse pregnancy, postpartum maternal and child health outcomes in Vietnam.

Participants This prospective cohort study included pregnant women seeking prenatal care at six hospitals in three large cities in Vietnam. After enrolment, eligible participants who gave their consent to participate in the study were interviewed at 24-28 weeks' gestation. Glucose testing was conducted and blood pressure was measured during this period. Each participant will be assessed prospectively during their postnatal visits at delivery, 1, 3, 6, 12, 18 and 24 months, and will be followed up for 5 years.

Findings to date of 2248 eligible pregnant women, 2030 were recruited (participation rate $90.3 \%$ ) between August 2015 and July 2016. All participants completed the baseline assessment. Their mean (SD) age was 27.6 (5.3) years. The mean pre-pregnancy body mass index (BMI) was 20.2 (SD 2.6) $\mathrm{kg} / \mathrm{m}^{2}$, with nearly two-thirds of participants having a normal pre-pregnancy BMI (18.5 to $<23.0 \mathrm{~kg} / \mathrm{m}^{2}$ ) and one-quarter being underweight (pre-pregnancy BMl $<18.5 \mathrm{~kg} / \mathrm{m}^{2}$ ). Overweight or obese mothers (pre-pregnancy BMl $\geq 23.0 \mathrm{~kg} / \mathrm{m}^{2}$ ) accounted for $12.8 \%$. No pregnant women reported smoking during their pregnancy while $13.4 \%$ of them had continued drinking. $22.8 \%$ of participants had hyperglycaemia. Their mean systolic blood pressure was 105.6 (SD 8.2) $\mathrm{mm} \mathrm{Hg}$, and diastolic blood pressure was 67.4 (SD 7.5) $\mathrm{mm} \mathrm{Hg}$.

Future plans The relationships of maternal lifestyle and nutritional status with the health outcomes of pregnancy, postpartum maternity and infants will be analysed. Meanwhile, participants will be closely tracked to minimise loss to follow-up.

\section{INTRODUCTION}

Pregnancy and the first 2years after giving birth are critical periods for mother and child health. Maternal lifestyle and dietary intake are known to be associated with metabolic disorders, such as gestational diabetes
Strengths and limitations of this study

- This is the first multicentre, prospective cohort study of maternal and child health in Vietnam, with a large sample size over a relatively long period of followup.

- The study investigates multiple modifiable maternal risk factors for adverse pregnancy, postpartum maternal and child health outcomes in Vietnam.

- All questionnaires used for data collection have been validated for Vietnamese people.

- Potentially high rates of loss to follow-up in more affluent settings.

Lack of participants from rural and remote areas.

mellitus (GDM). These conditions increase the risk of adverse pregnancy and infant health outcomes. ${ }^{12}$ In particular, overeating or sedentary behaviour during pregnancy has been positively associated with a risk of GDM. $^{3-6}$ Development of maternal GDM increases the risk of adverse health in mothers (gestational hypertension and pre-eclampsia, subsequent type 2 diabetes), ${ }^{2}$ in infants (stillbirth, macrosomia, neonatal hypoglycaemia) ${ }^{7}$ and in children (obesity, diabetes, hypertension and cardiovascular diseases). ${ }^{8}$

Vietnam is a middle-income country in Southeast Asia with a population of over 90 million. $^{9}$ It is undergoing epidemiological transition. A high burden of infectious diseases remains and the prevalence of chronic non-communicable diseases is increasing. The prevalence of overweight and obesity (BMI $\geq 23.0 \mathrm{~kg} / \mathrm{m}^{2}$ ) among Vietnamese adults has risen from $11.7 \%$ to $16.3 \%$ between 2000 and $2005 .{ }^{10}$ The prevalence of GDM is reported to range from $6.1 \%$ to $20.3 \%$, and women with GDM tend to deliver 
preterm. Thus the newborns have a higher incidence of neonatal hypoglycaemia, and labour induction is more prevalent. ${ }^{11}$ Although breastfeeding has significant benefits for infants and mothers, ${ }^{12}$ many Vietnamese people underestimate its advantages. The rate of exclusive breastfeeding during the first 6 months of life is low and decreased from $25.0 \%$ in 2000 to $17.0 \%$ in $2011 .{ }^{13}$ Notably, mothers with hyperglycaemia during pregnancy tend to have a high rate of exclusive breastfeeding cessation. ${ }^{14}$

Few prospective cohort studies of mothers and their infants have been conducted in Vietnam, ${ }^{11}{ }^{15-17}$ and the few which are underway are being carried out in single provinces with limited outcomes being investigated. Moreover, the available data on the relationship between maternal lifestyle, nutrition and adverse pregnancy, postpartum and child health outcomes are sparse. This research is the first multicentre prospective cohort study, representative of the Vietnamese population, which investigates broad aspects of modifiable maternal risk factors and their health consequences. The main objectives of this study are:

1. To investigate the lifestyle, nutritional and metabolic status of pregnant women in Vietnam, including physical activity, smoking, alcohol drinking, dietary intake, pre-pregnancy body mass index (BMI) and gestational weight gain.

2. To ascertain the impact of aforementioned maternal factors on (a) obstetric complications (eg, GDM, preeclampsia, pregnancy-induced hypertension); (b) pregnancy outcomes (eg, preterm delivery, caesarean section, low birth weight, macrosomia and postpartum haemorrhage) and (c) postpartum maternal and child health.

3. To examine the association between breastfeeding and (a) maternal metabolic conditions, including GDM; (b) postpartum maternal and infant health status.

4. To determine the relationship between antenatal and postnatal depressive symptoms and (a) pregnancy and birth outcomes; (b) breastfeeding intention and initiation; (c) the intensity and duration of breastfeeding; (d) infant care and adverse home events; (e) postpartum maternal and infant health status.

\section{COHORT DESCRIPTION}

\section{Study settings}

This ongoing prospective cohort study is conducted in three cities of Vietnam-namely, Ha Noi, Hai Phong and Ho Chi Minh cities. Ha Noi is the capital of Vietnam located in the north while Ho Chi Minh City is the largest and most industrialised city in the south. Hai Phong is a coastal city, located in the Red River delta. For Ha Noi and Hai Phong cities, one suburban district from each city was selected-the Dong Anh and Vinh Bao districts, respectively. Dong Anh has 23 communes and one town with a population of over 300000 people. ${ }^{18}$ Vinh Bao is a coastal district comprising 29 communes and one town with over 180000 people. ${ }^{19}$ For Ho Chi Minh City, two typical urban districts (Tan Phu district and District 2) and one typical suburban district (Hoc Mon district) were chosen. Tan Phu $\left(16.1 \mathrm{~km}^{2}\right)$ has 11 wards with a population of over 464000 people while District $2\left(49.7 \mathrm{~km}^{2}\right)$ consists of 11 wards and about 147000 people. ${ }^{20}$ Hoc Mon $\left(109.2 \mathrm{~km}^{2}\right)$ comprises one town and 11 communes with a population of approximately 422000 people. ${ }^{20}$ Each district has one district hospital that provides healthcare for the majority of its citizens in the catchment areas. Moreover, some pregnant women from Tan Phu, Hoc Mon and District 2 may directly visit Hung Vuong Hospital, a large provincial obstetric hospital, especially if their pregnancies have complications. Therefore, Hung Vuong Hospital was also selected to obtain details of participants from these three districts. A total of six hospitals participated in the study. Figure 1 shows the location of the centres and districts involved in the study.

\section{Participants and eligibility criteria}

Participants were pregnant women who satisfied the following criteria: (1) permanent residents in the study locations; (2) $\geq 18$ years of age; (3) at 24-28 weeks' gestation; (4) singleton pregnancy; (5) not having a serious pre-existing health condition, such as cancer, ischaemic heart disease according to information from their medical doctors; (6) able to read the information sheet and sign the consent form.

\section{Sample size}

The sample size calculation was based on testing the hypothesis that mothers with gestational hyperglycaemia (primary exposure) have a lower rate of exclusive breastfeeding at 3 months post partum (primary outcome). Assuming that $20 \%$ of participants would have gestational hyperglycaemia diagnosed at 24-28 weeks of gestation, ${ }^{21}$ and that the rates of exclusive breastfeeding at 3 months post partum among mothers with prior gestational hyperglycaemia and those without are $42 \%$ and $52 \%$, respectively, ${ }^{14}$ a minimum sample size of 1662 is required to attain $90 \%$ power to detect an expected OR of $0.7^{14}$ between the two groups $^{22}$ at $5 \%$ level of significance. We assumed a further $20 \%$ attrition, owing to withdrawal or subsequent loss to follow-up, and thus 2000 pregnant women were targeted for recruitment. Based on the population of three centres, ${ }^{23}$ the subsample sizes assigned to $\mathrm{Ha}$ Noi, Hai Phong and Ho Chi Minh City were 900, 300 and 800 , respectively. Participants were consecutively recruited from the three centres until their desired sampling quotas were reached.

\section{Data collection}

Baseline and postpartum follow-ups of study participants are currently being implemented. The study procedure is summarised in figure 2. 


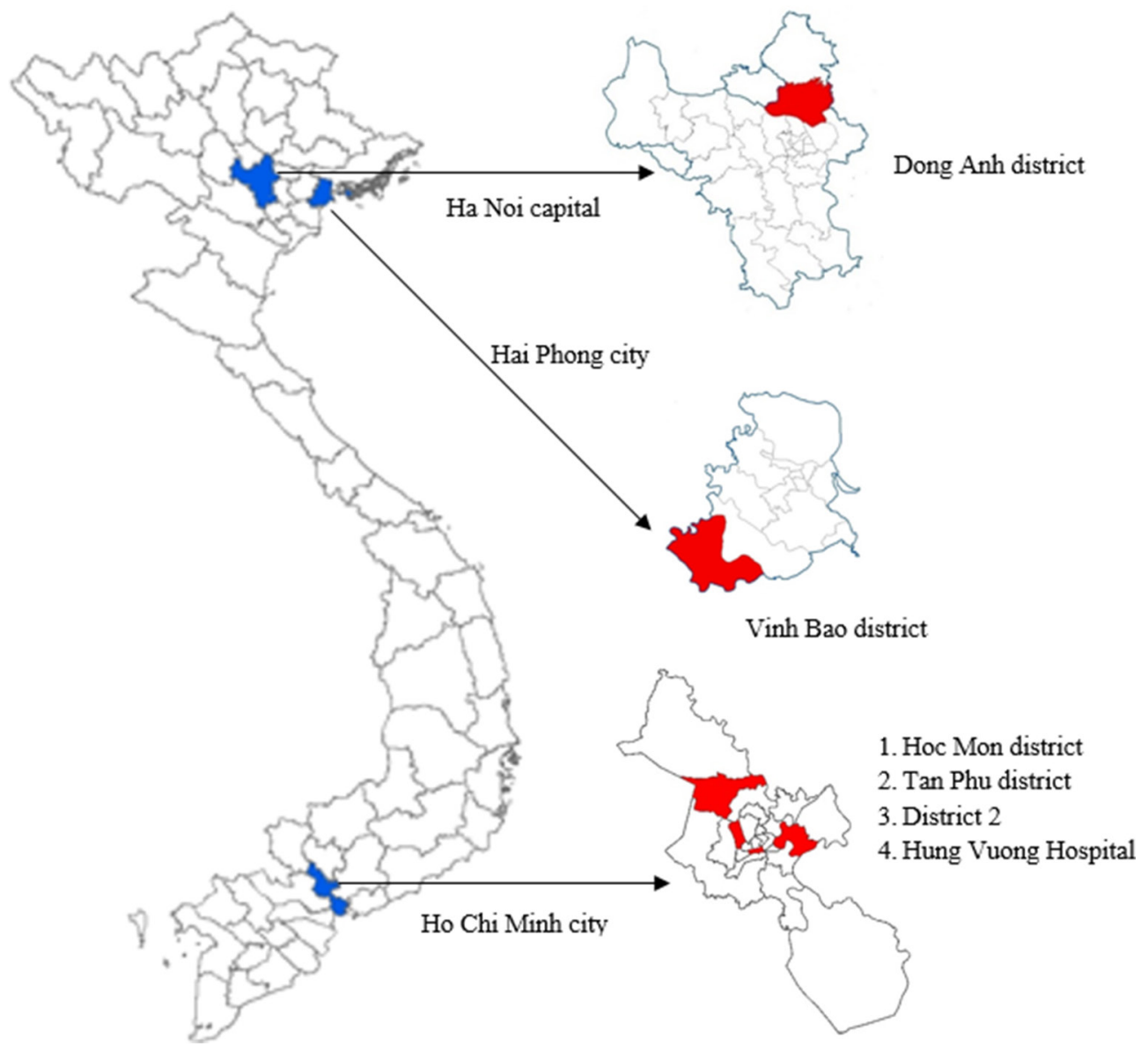

Figure 1 The location of study centres.

\section{Recruitment}

Recruitment began in August 2015 and ended in July 2016. During that period, all pregnant women from the participating hospitals were consecutively approached and invited to participate in the study if they met the eligible criteria. According to the Vietnam 2014 Multiple Indicator Cluster Survey, nearly 94\% of the pregnant women delivered in hospitals. ${ }^{24}$ Gestational age was determined using ultrasound during the first trimester and was available from medical records. A total of 2248 pregnant women who met the inclusion criteria were invited, $218(9.7 \%)$ refused participation, and 2030 (90.3\%) consented to take part in the study. No significant difference in mean age was found between participants and non-participants $(\mathrm{p}=0.991)$.

\section{Baseline interview at 24-28 gestation weeks}

After enrolment, pregnant women were interviewed face to face by trained personnel to obtain detailed information on demographic and personal characteristics, dietary intakes, lifestyle habits including physical activity, cigarette smoking and alcohol drinking, antenatal depressive symptoms and attitudes to breastfeeding. Standard or validated questionnaires for Vietnamese adults were used to collect information.

\section{Dietary assessment}

The Food Frequency Questionnaire for Vietnamese adults was applied to investigate habitual diet. ${ }^{25}$ It consists of various food and beverage items grouped into categories, with frequencies and quantities consumed recorded in detail. The frequency recorded is either per day, per week, per month or never, with a standard portion or utensil defined for each food/ beverage item listed.

\section{Physical activity assessment}

The Pregnancy Physical Activity Questionnaire (PPAQ) was used to examine physical activity. ${ }^{26}$ The PPAQ measures the duration, frequency and intensity of physical activity during pregnancy. It is a semiquantitative questionnaire that asks about the time spent participating in 32 activities, including household/ caregiving (13 activities), occupational (five activities), sports/exercise (eight activities), transportation (three activities) and inactivity (three sedentary activities). For each activity, respondents are asked to select a category with the closest amount of time spent per day or per week. The possible duration ranged from 0 to 6 or more hours a day. An open-ended section is appended to allow listing of additional activities not covered. 
$<20$ weeks of gestation

24-28 weeks of gestation

After birth and before
discharge

1 month

3 months

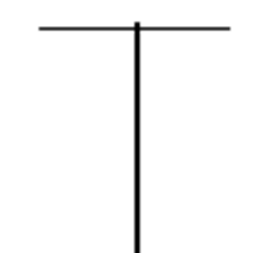

6 months

12 months

18 months

24 months

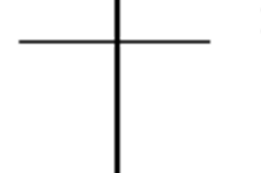

$\square$

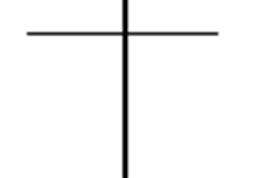

Recruitment

- 2248 pregnant women met the inclusion criteria were invited

- 218 refused

- 2030 consented

\section{Baseline interview}

- 2030 women participated

Birth and hospital discharge assessment

Follow-up survey

Follow-up survey

Follow-up survey

Follow-up survey

Follow-up survey

Follow-up survey

\section{Follow-up survey}

items. Total attitude scores range from 17 to 85 , with higher scores reflecting attitudes more positive towards breastfeeding. Total scores are grouped into three categories: positive towards breastfeeding (70-85), neutral (49-69) and positive towards formula feeding (17-48).

\section{Assessment of smoking and alcohol drinking}

Information on cigarette smoking and consumption of alcohol was acquired using WHO STEPS questions. ${ }^{31}$

Anthropometric assessment

Anthropometric measurements were made during the baseline interview. A digital scale was used to record weight to the nearest $100 \mathrm{~g}$. Height was measured using a stadiometer to the nearest $1 \mathrm{~mm}$. Data on pre-pregnancy weight, retrieved from medical records, were likely to be self-reported. Total gestational weight gain was estimated by subtracting the early first trimester weight from the last measured weight before delivery. Maternal BMI was 
calculated using weight and height recorded at baseline $\left(\mathrm{kg} / \mathrm{m}^{2}\right)$.

\section{Clinical assessment}

To determine maternal glucose-metabolic status, all pregnant women were required by the participating hospitals to undergo a $75 \mathrm{~g}$ oral glucose tolerance test between 24 and 28 weeks of gestation; three blood samples were collected at fasting, 60 and $120 \mathrm{~min}$. Confirmation of gestational diabetes mellitus was based on the 2013 diagnostic criteria of the World Health Ogarnization. ${ }^{32}$ To determine gestational hypertension, blood pressure was measured at the same time as the glucose tolerance test by qualified nurses or physicians using an Omron M5-1 electronic sphygmomanometer according to the WHO procedure. Participants were required to take a short rest (15 min), sitting, feet supported on a flat surface and arm supported at heart level. Two consecutive measurements were taken 3 min apart and a mean value was obtained. WHO diagnostic criteria for gestational hypertension were used. ${ }^{1}$ Information on pre-eclampsia was obtained from medical records. Details of obstetric complications during pregnancy were extracted from medical records.

\section{Birth and hospital discharge assessment}

At the time of delivery, details including obstetric and neonatal outcomes (eg, type of delivery, Apgar scores, problems/complications, intensive care treatment and length of hospital stay) will be recorded. Infants will be weighed to the nearest $10 \mathrm{~g}$ on an electronic scale immediately after birth. Length at birth will be measured on an infantometre. Other physical characteristics, such as head, abdominal and mid upper-arm circumference, will be measured within 72 hours after birth to the nearest $0.1 \mathrm{~cm}$ using a standardised measuring tape.

Mothers will be asked about breastfeeding initiation, prelacteal feeds (if any) and breastfeeding self-efficacy at this time using a standardised breastfeeding questionnaire $^{1533}$ and the Breastfeeding Self-Efficacy Scale (BSES).$^{30}$ The BSES is a 33-item, self-report instrument developed to measure breastfeeding confidence. The items are preceded by the phrase 'I can always' and anchored with a five-point Likert scale, where $1=$ not at all confident and $5=$ always confident. All items are presented positively, and scores are summed to produce a range from 33 to 165. A higher score indicates a stronger confidence in breastfeeding. They will be also interviewed about depressive symptoms using the EPDS.

\section{Follow-up surveys}

All mothers will be assessed during their postnatal visits at delivery, 1, 3, 6, 12, 18 and 24 months post partum. Detailed information on infant feeding practices, infant illnesses, anthropometrics, maternal depressive symptoms, maternal diet and physical activity, and other health problems of both mothers and infants will be sought at subsequent follow-ups of the cohort. The follow-up interviews will be conducted at community health centres or at the mother's home. A 48-hour food diary will be used to record the consumption of breast milk, formula, foods and beverages by the infants at 1,3, and 6 months of age. Symptoms of illness of the child such as fever, infection and diarrhoea, and length of hospitalisation will also be documented in detail based on both self-report and/or medical records.

A follow-up study on these children up to 5 years of age is planned and subject to funding availability.

\section{Statistical analysis}

Data will be pooled and combined across study sites. After data screening and cleaning, descriptive statistics will be used to characterise study participants. Group comparisons will be undertaken using $\mathrm{X}^{2}$ tests for categorical variables, and either t tests/analysis of variance or MannWhitney $\mathrm{U}$ tests for continuous variables. Independent variables include demographic factors, medical history and maternal lifestyle such as dietary intake, physical activity, smoking and alcohol drinking. The main dependent variables of interest are gestational diabetes status, pregnancy outcomes (eg, stillbirth, pre-eclampsia), delivery outcomes (eg, low birth weight, macrosomia, preterm birth, caesarean section), breastfeeding duration, depressive symptom scores, gestational weight gain and postpartum weight retention, infant growth and child health conditions.

Logistic or Poisson regression models will be fitted to investigate the relationships between selected exposures and binary or discrete outcomes measured at a single point in time. Mixed regression analyses with random effects will be undertaken to assess the association between plausible risk factors and the longitudinal outcomes, such as depressive symptom scores and infant weight, while accounting for the repeated measures and clustering of subjects within study sites (hospitals). Kaplan-Meier test and Cox regression will be performed to determine the effects of influencing factors on the breastfeeding duration. Crude and adjusted coefficients or OR estimates and associated $95 \%$ confidence intervals will be reported for regression analyses, and adjusted hazard ratios for survival random-effects models.

Potential confounding variables will be selected with reference to the literature and modelling strategies. ${ }^{34} 35$ For instance, to assess the association between gestational diabetes and rates of exclusive breastfeeding, possible confounders might be parity, delivery type, birth weight, ${ }^{14}$ in addition to demographic factors, energy intake, energy expenditure and other covariates. Effect modification will also be taken into account in the statistical modelling. All statistical analyses will be performed using the SPSS package version 22 (IBM, Armonk, New York, USA).

\section{Ethics and dissemination}

The project has been approved by the Curtin University human research ethics committee (HR32/2015) and the Hai Phong University of Medicine and Pharmacy human research ethics committee (No 05/HPUMPRB/2015). 
All participants have been provided with verbal and written information on the study describing its purpose and their requirements. Each participant has a unique ID number with basic information, including name, address, and phone numbers of themselves and partners so that they can be followed up later. Participants could withdraw from the study at any time without prejudice. All identifiable information of participants has been coded and securely stored. Study results will be published in academic journals.

\section{FINDINGS TO DATE}

Baseline characteristics of participants are summarised in table 1.

The 2030 pregnant women had a mean age of 27.6 (SD $5.3)$ years (range 18-48 years). The majority $(60.6 \%)$ of women were in the age group 25-35 years in all locations. Almost all of the subjects were married (99.3\%). Manual work and farming were the main occupations $(54.9 \%)$ of the participants, followed by office and technical staff $(22.5 \%)$. More than $60 \%$ of the mothers had completed high school and over one-third of them had a degree from college or university. Women in Ha Noi had the highest level of advanced educational level (50.9\%) while Ho Chi Minh City had the highest rate of low educational level $(18.5 \%)$. A majority $(61.8 \%)$ of the participants had a normal pre-pregnancy BMI (18.5 to $<23 \mathrm{~kg}$ / $\mathrm{m}^{2}$ ) and mean BMI was $20.2 \mathrm{~kg} / \mathrm{m}^{2}$ (SD 2.6). The prevalence of normal BMI was similar among the three centres. However, Ho Chi Minh City had a substantially higher rate of overweight and obesity $(20.8 \%)$ while Hai Phong city had a higher rate of underweight $(31.7 \%)$. About one-quarter of the pregnant women were underweight. This rate was similar to a study in Ha Nam $(26 \%)^{36}$ and in Nha Trang $(26.1 \%) .{ }^{16}$ No pregnant women smoked during pregnancy but more than one-half were exposed to passive smoking at home. The overall prevalence of alcohol consumption during pregnancy was $13.4 \%$ and the highest proportion of women consuming alcohol was found in Ha Noi with $18.0 \%$.

Very few participants had a history of hypertension or pre-eclampsia in each site. During their last pregnancy, the rate of GDM was $1.4 \%$, birth defects $(1.8 \%)$, macrosomia $(3.6 \%)$ or preterm delivery $(6.3 \%)$. The reported rates of stillbirth, abortion and caesarean section were $10.4 \%, 17.9 \%$, and $21.5 \%$, respectively.

Analysis of the blood test of 2023 participants (excluding seven patients with diabetes before pregnancy) showed that the prevalence of hyperglycaemia was $22.8 \%$, slightly lower than found in a previous cohort study in southern Vietnam. ${ }^{21}$ The hyperglycaemia rate was highest in Ho Chi Minh City (31.0\%), followed by Hai Phong (19.9\%) and Ha Noi (16.4\%). The mean systolic blood pressure in all centres was $105.6(\mathrm{SD} \mathrm{8.2)} \mathrm{mm} \mathrm{Hg}$, and the mean diastolic blood pressure was 67.4 (SD 7.5) $\mathrm{mm} \mathrm{Hg}$.

Data on physical activity, dietary pattern, breastfeeding and antenatal depressive symptoms are currently being analysed and results will be presented in subsequent articles.

\section{STRENGTHS AND LIMITATIONS}

One major strength of this multicentre, prospective cohort study in Vietnam is its large number of patients, followed up over a relatively long period; it is conducted in two principal regions of Vietnam, thus representing the urban Vietnam population. The few previous prospective cohort studies undertaken in Vietnam were either conducted in a single province, ${ }^{11} 15-1737$ or their sample sizes were small ${ }^{1517}$ or their follow-up times were short. ${ }^{117}$

Another strength is that it investigates a variety of modifiable maternal risk factors for adverse pregnancy, postpartum maternal and child health outcomes in Vietnam. Unlike previous prospective studies in Vietnam, ${ }^{11} 1737$ this project examines lifestyle, nutritional and metabolic status of pregnant women, including physical activity, smoking, alcohol drinking, dietary intake, pre-pregnancy BMI, gestational weight gain, antenatal and postnatal depressive symptoms and breastfeeding. It will also ascertain the impact of maternal factors (eg, pre-pregnancy BMI, dietary intake, physical activity, gestational weight gain) on obstetric complications (eg, gestational diabetes mellitus, pre-eclampsia, pregnancy-induced hypertension), pregnancy outcomes (eg, preterm delivery, caesarean section, low birth weight, macrosomia and postpartum haemorrhage), postpartum health status (eg, postnatal depressive symptoms, morbidity) and child health and growth for at least 2 years.

The results of our study will provide new evidence on the impact of diet and physical activity on delivery and postpartum health outcomes in Vietnamese women, which can be compared with findings from other developing and developed countries. The research findings will provide significant information for the development of guidelines, policy planning and advocacy, and can be used to formulate appropriate intervention programmes to improve maternal and child health in Vietnam. In addition, all questionnaires used for data collection have been validated for the Vietnamese people, thereby increasing the accuracy of the information.

This study has several weaknesses. First, pregnant women were recruited from hospitals, which may present some selection bias. However, the participation rate was high $(90.3 \%)$ and thus selection bias should be negligible. Second, recall errors and bias in the assessments of physical activity and dietary intake cannot be ruled out. Nevertheless, we minimise these impacts by using validated questionnaires and experienced interviewers. Third, although contact information of participants and their partners, such as addresses and mobile phone numbers have been recorded, a high rate of attrition in an industrialised city like Ho Chi Minh City is expected. This limitation is reduced by maintaining a regular good relationship with participants during the follow-up. Finally, although farming respondents are recruited from 
Table 1 Baseline characteristics of participants

\begin{tabular}{|c|c|c|c|c|}
\hline & Ha Noi $\left(n_{1}=905\right)$ & Hai Phong $\left(n_{2}=298\right)$ & Ho Chi Minh $\left(n_{3}=827\right)$ & Total $(n=2030)$ \\
\hline Variables & n (\%) & n (\%) & n (\%) & n (\%) \\
\hline \multicolumn{5}{|l|}{ Age (years) } \\
\hline 25-35, n (\%) & $499(55.1)$ & $178(59.7)$ & 553 (66.9) & $1230(60.6)$ \\
\hline$>35, \mathrm{n}(\%)$ & $60(6.6)$ & $23(7.7)$ & $80(9.7)$ & $163(8.0)$ \\
\hline Marital status (married) & $902(99.7)$ & $294(98.7)$ & $819(99.0)$ & 2015 (99.3) \\
\hline \multicolumn{5}{|l|}{ Occupation } \\
\hline Famers & $194(21.4)$ & $44(14.8)$ & $58(7.0)$ & 296 (14.6) \\
\hline Workers & 303 (33.5) & 139 (46.6) & $376(45.5)$ & $818(40.3)$ \\
\hline Office and technical staff & $226(25.0)$ & $44(14.8)$ & $186(22.5)$ & $456(22.5)$ \\
\hline \multicolumn{5}{|l|}{ Educational level } \\
\hline Under secondary & $15(1.7)$ & $3(1.0)$ & $153(18.5)$ & $171(8.4)$ \\
\hline Secondary & $164(18.1)$ & 98 (32.9) & 289 (34.9) & $551(27.1)$ \\
\hline High school & 265 (29.3) & $88(29.5)$ & $172(20.8)$ & $525(25.9)$ \\
\hline College/university & 461 (50.9) & 109 (36.6) & $213(25.8)$ & 783 (38.6) \\
\hline \multicolumn{5}{|l|}{ Parity } \\
\hline 0 & 361 (39.9) & 105 (35.2) & $323(39.1)$ & 789 (38.9) \\
\hline 1 & $306(33.8)$ & $110(36.9)$ & $340(41.1)$ & 756 (37.2) \\
\hline$\geq 2$ & 238 (26.3) & $83(27.9)$ & $164(19.8)$ & 485 (23.9) \\
\hline
\end{tabular}

Body mass index (BMI) before pregnancy $\left(\mathrm{kg} / \mathrm{m}^{2}\right)^{*}$ $(n=2010)$

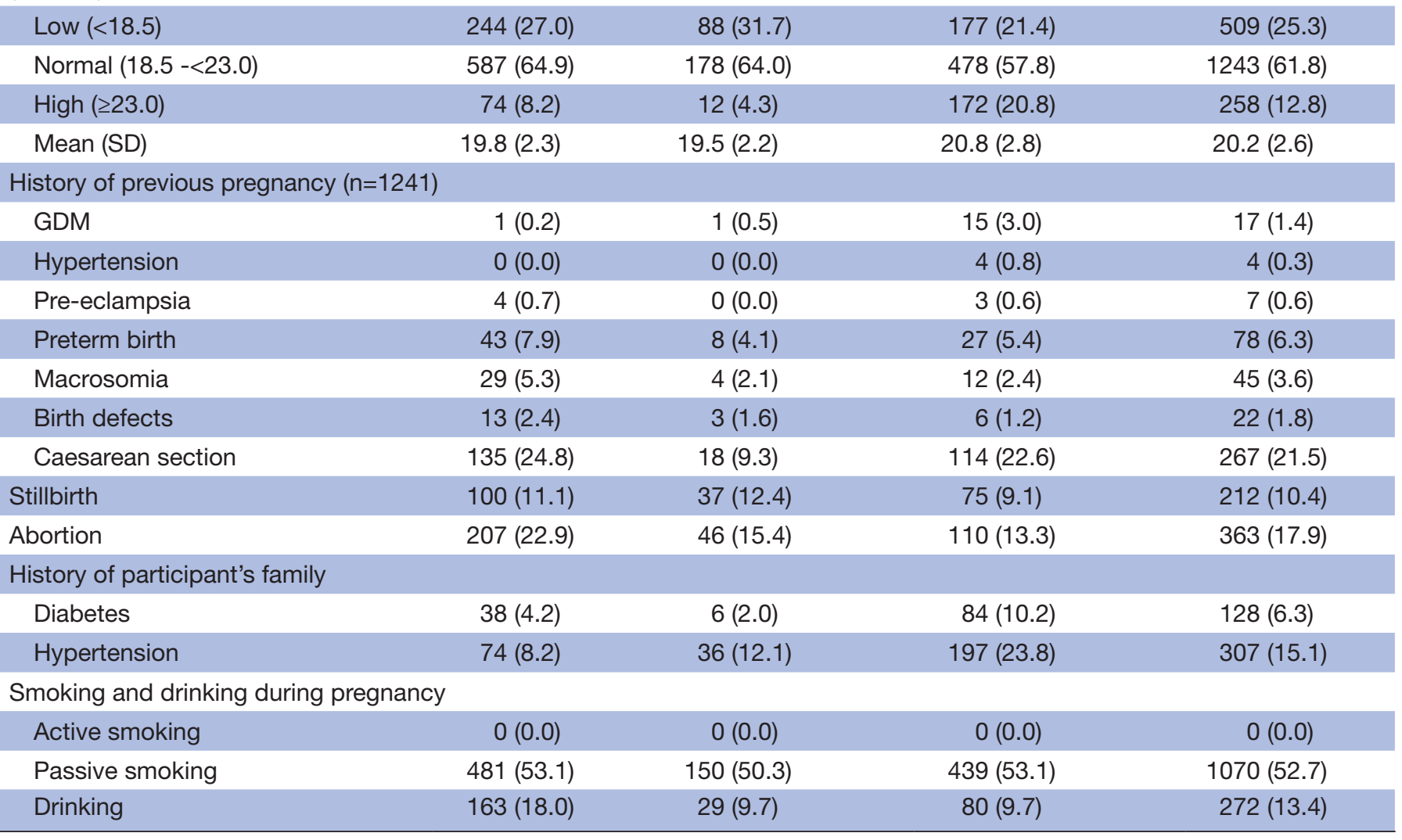


Table 1 Continued

\begin{tabular}{lcccc}
\hline & Ha Noi $\left(\mathbf{n}_{\mathbf{1}}=\mathbf{9 0 5}\right)$ & Hai Phong $\left(\mathbf{n}_{\mathbf{2}}=\mathbf{2 9 8}\right)$ & Ho Chi Minh $\left(\mathbf{n}_{\mathbf{3}}=\mathbf{8 2 7}\right)$ & Total $(\mathbf{n}=\mathbf{2 0 3 0})$ \\
\cline { 2 - 5 } Variables & $\mathbf{n}(\%)$ & $\mathbf{n}(\%)$ & $\mathbf{n}(\%)$ & $\mathbf{n}(\%)$ \\
\hline Blood glucose test (n=2023) & & & & \\
$\quad$ Fasting (mean, SD) & $4.4(0.5)$ & $4.4(0.7)$ & $4.5(0.4)$ & $4.5(0.5)$ \\
1-Hour 75g OGTT (mean, SD) & $7.2(1.8)$ & $6.9(1.6)$ & $8.4(1.8)$ & $7.6(1.9)$ \\
2-Hour 75 OGTT (mean, SD) & $6.4(1.5)$ & $6.1(1.3)$ & $7.3(1.5)$ & $6.7(1.6)$ \\
Hyperglycaemia† & $148(16.4)$ & $59(19.9)$ & $255(31.0)$ & $462(22.8)$ \\
Blood pressure & & & & $105.6(8.2)$ \\
Systolic, mm Hg (mean, SD) & $105.0(7.3)$ & $107.0(8.3)$ & $105.8(9.0)$ & $67.4(7.5)$ \\
Diastolic, mm Hg (mean, SD) & $64.9(6.4)$ & $64.3(6.1)$ & $71.3(7.3)$ & $88.7(11.5)$ \\
\hline Pulse, bpm (mean, SD) & $84.3(9.3)$ & $79.3(6.0)$ & $97.0(9.9)$ & \\
\hline
\end{tabular}

Results are shown as number (\%) unless stated otherwise.

${ }^{*} \mathrm{BMl}$ cut-off for Asian population was used. ${ }^{38}$

†Hyperglycaemia was classified by WHO $2013 .^{32}$

GDM, gestational diabetes mellitus; OGTT, oral glucose tolerance test.

suburban districts, they may not represent rural women in the country.

\section{Author affiliations}

${ }^{1}$ National Expanded Program on Immunization, National Institute of Hygiene and

Epidemiology, Ha Noi, Vietnam

${ }^{2}$ University of Medicine and Pharmacy, Ho Chi Minh City, Vietnam

${ }^{3}$ Hai Phong University of Medicine and Pharmacy, Hai Phong, Vietnam

${ }^{4}$ Pham Ngoc Thach University of Medicine, Ho Chi Minh City, Vietnam

${ }^{5}$ Thai Nguyen University of Medicine and Pharmacy, Thai Nguyen, Vietnam

${ }^{6}$ United Nations Population Fund, Ha Noi, Vietnam

${ }^{7}$ School of Public Health, Curtin University, Perth, Australia

Acknowledgements The authors acknowledge the study participants for their participation and continuing support. They are deeply grateful to the participating hospitals for their support in data collection.

Collaborators There is room for future joint studies. This study will follow-up mothers and their babies until 2 years post partum. This duration can be extended to investigate the effects of maternal factors on the health problems of mothers and their children later in life. In addition, the study is currently performing in two regions (Red River Delta and Southeast), while Vietnam has six socioecological regions. It can be expanded into other regions to increase the sample size and representation. Therefore, the study welcomes all researchers who have the same objectives together with available funding. Study proposals must be submitted to the study research team for review and approval.

Contributors CLN, PTHN, TKC, and AVVH participated in the study design and data collection. CLN wrote the draft and edited the manuscript. TKC performed the baseline analysis. NMP provided expert advice on the draft of the manuscript. DVDu, DVDo, HKT, AHL, and CWB were the study supervisors and involved in all aspects of the study. All the authors revised the article and approved the final version to be published.

Funding This study was financially supported by the School of Public Health, Curtin University, Perth, Western Australia, Australia.

Competing interests None declared.

Patient consent Obtained.

Ethics approval The study was approved by the Curtin University human research ethics committee (approval number: HR32/2015) and the Hai Phong University of Medicine and Pharmacy human research ethics committee (approval number: 05/ HPUMPRB/2015).

Provenance and peer review Not commissioned; externally peer reviewed.

Data sharing statement Researchers can access to the cohort data by sending us an applicationvia email () for discussion andapproval at the research team meeting.
Open Access This is an Open Access article distributed in accordance with the Creative Commons Attribution Non Commercial (CC BY-NC 4.0) license, which permits others to distribute, remix, adapt, build upon this work non-commercially, and license their derivative works on different terms, provided the original work is properly cited and the use is non-commercial. See: http://creativecommons.org/ licenses/by-nc/4.0/

(C) Article author(s) (or their employer(s) unless otherwise stated in the text of the article) 2017. All rights reserved. No commercial use is permitted unless otherwise expressly granted.

\section{REFERENCES}

1. Roberts JM, Pearson GD, Cutler JA, et al. Summary of the NHLBI Working Group on Research on Hypertension During Pregnancy. Hypertens Pregnancy 2003;22:109-27.

2. Ashwal E, Hod M. Gestational diabetes mellitus: where are we now? Clin Chim Acta 2015;451:14-20.

3. Dempsey JC, Butler CL, Sorensen TK, et al. A case-control study of maternal recreational physical activity and risk of gestational diabetes mellitus. Diabetes Res Clin Pract 2004:66:203-15.

4. Dempsey JC, Sorensen TK, Williams MA, et al. Prospective study of gestational diabetes mellitus risk in relation to maternal recreational physical activity before and during pregnancy. Am J Epidemiol 2004;159:663-70 http://www.ncbi.nlm.nih.gov/pubmed/15033644.

5. Guelinckx I, Devlieger R, Beckers K, et al. Maternal obesity: pregnancy complications, gestational weight gain and nutrition. Obes Rev 2008;9:140-50.

6. Mehta SH. Nutrition and pregnancy. Clin Obstet Gynecol 2008;51:409-18.

7. Siega-Riz AM, Viswanathan M, Moos MK, et al. A systematic review of outcomes of maternal weight gain according to the Institute of Medicine recommendations: birthweight, fetal growth, and postpartum weight retention. Am J Obstet Gynecol 2009;201:339. e1-14.

8. Spencer SJ. Early life programming of obesity: the impact of the perinatal environment on the development of obesity and metabolic dysfunction in the offspring. Curr Diabetes Rev 2012;8:55-68 http:// www.ncbi.nlm.nih.gov/pubmed/22352445.

9. General Statistics Office of Vietnam. 2015. Population change and family planning survey Hanoi Vietnam: General Statistics Office, 2016.

10. Ha do TP, Feskens EJ, Deurenberg P, et al. Nationwide shifts in the double burden of overweight and underweight in Vietnamese adults in 2000 and 2005: two national nutrition surveys. BMC Public Health 2011:11:62.

11. Hirst JE, Tran TS, Do MA, et al. Consequences of gestational diabetes in an urban hospital in Viet Nam: a prospective cohort study. PLoS Med 2012;9:e1001272. 
12. World Health Organization. 10 facts on breastfeeding. 2015 http:// www.who.int/features/factfiles/breastfeeding/en/ (cited 10 Dec 2016).

13. Bui QT, Lee HY, Le AT, et al. Trends and determinants for early initiation of and exclusive breastfeeding under six months in Vietnam: results from the Multiple Indicator Cluster Surveys, 2000-2011. Glob Health Action 2016;9:29433.

14. Verd S, de Sotto D, Fernández $\mathrm{C}$, et al. The effects of mild gestational Hperglycemia on exclusive breastfeeding Cssation. Nutrients 2016:8:742.

15. Duong DV, Lee AH, Binns CW. Determinants of breastfeeding within the first 6 months post-partum in rural Vietnam. J Paediatr Child Health 2005;41:338-43.

16. Ota E, Haruna M, Suzuki M, et al. Maternal body mass index and gestational weight gain and their association with perinatal outcomes in Viet Nam. Bull World Health Organ 2011;89:127-36.

17. Hanieh S, Ha TT, De Livera AM, et al. Antenatal and early infant predictors of postnatal growth in rural Vietnam: a prospective cohort study. Arch Dis Child 2015;100:165-73.

18. People's committee of Dong Anh District. General information on Dong Anh district. 2013 http://donganh.hanoi.gov.vn/thong-tinchung/-/news/NYj802SetZla/1/2704.html (cited 10 December 2016).

19. People's committee of Vinh Bao District. General information on Vinh Bao district. 2008 http://haiphong.gov.vn/Portal/Detail.aspx? Organization=HVB\&MenulD $=1667 \&$ ContentID $=4759$.

20. Ho Chi Minh City Statistical Office. Ho Chi Minh City Statistical Yearbook 2015. Ho Chi Minh city: Statistical Publishing House, 2016. http://www.pso.hochiminhcity.gov.vn/web/guest/niengiamthongkenam2015.

21. Tran TS, Hirst JE, Do MA, et al. Early prediction of gestational diabetes mellitus in Vietnam: clinical impact of currently recommended diagnostic criteria. Diabetes Care 2013;36:618-24.

22. Was KJL, Evans AS, Thompson WD. Methods in observational epidemiology. 2nd edn. New York: Oxford University Press, 1996

23. General Statistics Office. Statistical handbook of Vietnam. Hanoi: Statistical publishing house, 2015. http://gso.gov.vn/default.aspx? tabid $=512$ \&idmid $=5 \& \mid$ tem $\mathrm{D}=16051$.

24. General Statistics Office and UNICEF. Viet Nam Multiple Indicator Cluster Survey 2014, Final Report: Ha Noi, Viet Nam, 2015.

25. Tran DH, DV.; Nguyen CT, Lee AH. Validity and reliability of a food frequency questionnaire to assess habitual dietary intake in Northern Vietnam. Vietnam Journal of Public Health 2013;1:57-65.
26. Ota E, Haruna M, Yanai $\mathrm{H}$, et al. Reliability and validity of the Vietnamese version of the Pregnancy Physical Activity Questionnaire (PPAQ). Southeast Asian J Trop Med Public Health 2008;39:562-70 http://www.ncbi.nlm.nih.gov/pubmed/18564699.

27. Tran TD, Tran T, La B, et al. Screening for perinatal common mental disorders in women in the north of Vietnam: a comparison of three psychometric instruments. J Affect Disord 2011;133:281-93.

28. Mora Adela, Russell DW, Dungy Cl, et al. The lowa infant feeding attitude scale: analysis of reliability and validity. J Appl Soc Psychol 1999;29:2362-80.

29. Chambers JA, Mclnnes RJ, Hoddinott P, et al. A systematic review of measures assessing mothers' knowledge, attitudes, confidence and satisfaction towards breastfeeding. Breastfeed Rev 2007;15:17-25 http://www.ncbi.nlm.nih.gov/pubmed/18062138.

30. Mongensen HF W. Breastfeeding among Vietnamese women in Ho Chi Minh City: attitudes and confidence: Department of Public Health and Caring Sciences, Uppsala University, 2009.

31. World Health Organization. WHO STEPS Instrument (Core and Expanded). 2008 http://www.who.int/chp/steps/instrument/STEPS_ Instrument V3.1.pdf?ua=1.

32. World Health Organization. Diagnostic criteria and classification of hyperglycaemia first detected in pregnancy. 2013 http://www.who. int/diabetes/publications/Hyperglycaemia_In_Pregnancy/en/.

33. DV, Binns CW, Lee AH. Breastfeeding initiation and exclusive breastfeeding in rural Vietnam. Public Health Nutr 2004;7:795-9 http://www.ncbi.nlm.nih.gov/pubmed/15369619.

34. Greenland S, Pearce N. Statistical foundations for model-based adjustments. Annu Rev Public Health 2015;36:89-108.

35. Greenland S, Daniel R, Pearce N. Outcome modelling strategies in epidemiology: traditional methods and basic alternatives. Int $J$ Epidemiol 2016;45:565-75.

36. Hanieh S, Ha TT, Simpson JA, et al. Postnatal growth outcomes and influence of maternal gestational weight gain: a prospective cohort study in rural Vietnam. BMC Pregnancy Childbirth 2014;14:339.

37. Nguyen PH, Lowe AE, Martorell R, et al. Rationale, design, methodology and sample characteristics for the Vietnam preconceptual micronutrient supplementation trial (PRECONCEPT): a randomized controlled study. BMC Public Health 2012;12:898.

38. WHO expert consultation. Appropriate body-mass index for Asian populations and its implications for policy and intervention strategies. Lancet 2004;363:157-63. 